\title{
The in vitro effect of zinc on the inhibition of human $\delta$-aminolevulinic acid dehydratase by lead
}

\author{
E. A. BORDER, A. C. CANTRELL, and T. A. KILROE-SMITH \\ National Research Institute for Occupational Diseases of the South African Medical Research \\ Council, P.O. Box 4788, Johannesburg 2000
}

\begin{abstract}
Border, E. A., Cantrell, A. C., and Kilroe-Smith, T. A. (1976). British Journal of Industrial Medicine, 33, 85-87. The in vitro effect of zinc on the inhibition of human $\delta$-aminolevulinic acid dehydratase by lead. The antagonistic effect of zinc on inhibition of human aminolevulinic acid dehydratase (ALAD) by lead was examined in vitro. The phenomenon was studied at pH 6-5-7.5. Zinc and lead were added at concentrations ranging from physiological levels to levels far in excess of those expected in heavy industrial exposure. ALAD activity of normal blood assayed in the presence of zinc was unaffected by exogenous lead if the added zinc concentration was above $0.53 \mathrm{mmol} / \mathrm{l}$ blood. If zinc was added at $0.15 \mathrm{mmol} / \mathrm{l}$ blood, the total zinc concentration was approximately $0.28 \mathrm{mmol} / \mathrm{l}$ blood, or double the normal endogenous level, and was of the order found in heavy industrial exposure to zinc. In this case, ALAD assay values were appreciably raised and might have fallen into the normal range in spite of a dangerous total blood lead of over $0.0048 \mathrm{mmol} / 1$. When zinc was added in vitro to blood from a worker with a blood lead level of $0.0043 \mathrm{mmol} / \mathrm{l}$ the ALAD values obtained were also raised and did not reflect the dangerous level of lead in the patient.
\end{abstract}

Recent reports (Abdulla and Haeger-Aronsen, 1973; Meredith, Moore, and Goldberg, 1974) have emphasized the complex interrelationship that exists between the various metal ions which affect the activity of aminolevulinic acid dehydratase (ALAD;EC 4.2.1.24). Whereas the enzyme is regarded primarily as a useful indicator of lead exposure in man, other metal ions can influence its activity. Abdulla and Haeger-Aronsen (1973) showed that while copper, cadmium, and mercury had a similar effect as lead in inhibiting the human enzyme in vitro, the activating effect of zinc (Abdulla and HaegerAronsen, 1971) could override this inhibition. Meredith et al. (1974) showed a similar effect with rats in vivo where zinc and aluminium both had an antagonistic effect on ALAD inhibition by lead.

Previous findings (unpublished) in this laboratory have shown that zinc activation of ALAD varies with $\mathrm{pH}$. The present study is aimed at assessing the effect of zinc on the activity of ALAD inhibited by lead at $\mathrm{pH}$ values in the range 6-5-7.5. Lead and zinc were added at concentrations ranging from the normal physiological levels, through those expected in heavy industrial exposure, to non-physiological levels. Results are compared with those obtained by the in vitro zinc activation of ALAD in blood from an industrial worker with heavy lead exposure. The significance of the results as they affect both the ALAD assay itself and patients with mixed zinc/lead exposure is discussed.

\section{Materials and methods}

Heparinized blood was obtained from normal donors with no known exposure either to lead or zinc, and an industrial worker with.recent intoxication by lead. Enzyme 
activity was determined by the method of Burch and Siegel (1971) modified as follows:

Incubation mixtures comprising:

$0.5 \mathrm{ml}$ sodium phosphate buffer $(0.25 \mathrm{M})$ at $\mathrm{pH}$ values ranging from $6.5-7.5$ at $0.2 \mathrm{pH}$ intervals,

$0.9 \mathrm{ml}$ haemolysate $(2 \mathrm{ml}$ blood $+13 \mathrm{ml} 0.2 \%$ Triton $\mathrm{X}-100$ ),

$0.2 \mathrm{ml}$ test metal(s) solution or $0.2 \mathrm{ml}$ water (control).

After preincubation for 30 minutes at $37^{\circ} \mathrm{C}, 0.1 \mathrm{ml}$ aminolevulinic acid hydrochloride $(0.06 \mathrm{M})$ was added to start the reaction. Incubation was at a temperature of $37^{\circ} \mathrm{C}$ for 1 hour. The reaction was stopped with $1.3 \mathrm{ml}$ of $10 \% \mathrm{TCA} / 0.02 \mathrm{M} \mathrm{N}$-ethylmaleimide solution, and porphobilinogen (PBG) was determined in the supernatant at $555 \mathrm{~nm}$ using modified Ehrlich's reagent.

Test ions were added to the assay in the form of aqueous solutions of analytical grade lead nitrate and zinc acetate. Lead and zinc were determined in the blood specimens using a Beckman 444 atomic absorption spectrophotometer.

\section{Results}

Effect of lead and zinc on ALAD activity in vitro The mean level of endogenous zinc in all specimens was found to be $0 \cdot 131 \mathrm{mmol} / \mathrm{l}$, which was within the normally accepted range of $0 \cdot 11-0.14 \mathrm{mmol} / 1$. The values for endogenous lead fell within the normal range for an urban population (1·0-2.0 $\mu \mathrm{mol} / \mathrm{l})$.

In experiments 1 (A-D) (Fig. 1) exogenous lead and zinc were added at arbitrary concentrations while experiment 1(E) was designed to imitate a hypothetical industrial situation with total lead at a dangerous level and total zinc at double the normal level. This zinc concentration was equal to the highest zinc value obtained by the National Research Institute for Occupational Diseases during a survey of workers at a zinc smelter.

In these five experiments the ALAD activity of the blood specimens used ranged from 287 to 1016 (mean 543) $\mu \mathrm{mol} \mathrm{PBG} / \mathrm{h}$ per 1 red blood cells (RBC) at pH 6.9, which is of the same order as the series used by Abdulla and Haeger-Aronsen (1973) (526-1166, mean 871). To compare the activating effect of the various zinc concentrations and to eliminate the variation in the control curves over the $\mathrm{pH}$ range, all values were expressed (Fig. 1) as a percentage of the corresponding control value at that specific $\mathrm{pH}$.

Lead inhibited ALAD activity in vitro at all the concentrations and over the whole pH range (Fig. 1). Zinc was able to activate the enzyme at all $\mathrm{pH}$ values at the various levels tested, the degree of activation being proportional to the exogenous zinc concentration and usually greater at the lower end of the pH range. At the lowest zinc concentration this activation was minimal (Fig. 1C, D). This level of added zinc was equivalent to $0.0054 \mathrm{mmol} / \mathrm{l}$ whole blood, however, which was lower than the 0.046 mmol/1 which Abdulla and Haeger-Aronsen (1971)
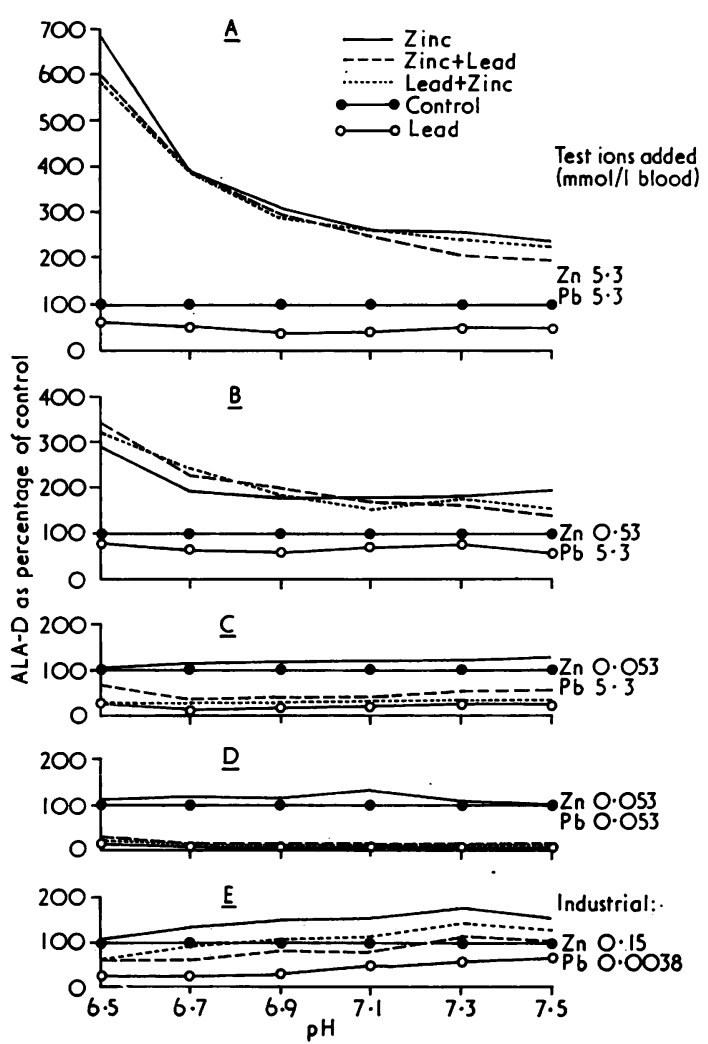

FIG. 1. The antagonistic effect of zinc on the inhibition of ALAD by lead at various $\mathrm{pH}$ values.

claimed to have an inhibitory effect on ALAD.

The antagonistic effect of zinc on the inhibition of ALAD by lead conformed to reported observation (Abdulla and Haeger-Aronsen, 1973; Meredith et al., 1974) and operated over the whole $\mathrm{pH}$ range studied. Zinc added to the assay at 5.3 and 0.53 mmol/1 whole blood completely overcame the inhibitory effect of $5.3 \mathrm{mmol} \mathrm{Pb} / 1$ whole blood, the resulting levels of activity being equal to those of the enzyme activated by zinc alone (Fig. 1A-B). However, the lowest zinc level was not able to overcome either this lead inhibition (Fig. 1C) or the inhibitory effect of an equimolar lead concentration (Fig. 1D), indicating that the activating effect observed in Fig 1A-B was not dependent solely on the exogenous molar ratios of zinc and lead, but appeared to require a threshold level of zinc. It should also be noted that there is apparently no significant difference in the antagonistic effect if zinc is added to the assay mixture before or after the addition of lead. Therefore it appears that neither the activation nor the inhibition reaction is irreversible in vitro. 
In the case of experiment $1(\mathrm{E})$, zinc was added at an intermediate level equivalent to that encountered in vivo. In that case the antagonistic effect was significant, although the final activity was not equal to that obtained by zinc alone. This experiment showed that a large molar excess of exogenous zinc over lead was not able to antagonize the inhibition of lead completely. This emphasized that the antagonistic effect did not depend on a direct stoichiometric relationship between inhibiting and activating ions.

The in vitro effect of zinc on ALAD activity in a worker with dangerous lead exposure

The previous experiments were extended to investigate the effect of zinc on ALAD estimation in the blood of a worker who had recently been removed from high lead exposure.

A 24-year-old man, showed the following clinical features: blood lead, $4.3 \mu \mathrm{mol} / 1$ blood; PCV, 38; urinary aminolevulinic acid (ALA); $0.27 \mathrm{mmol} / \mathrm{l}$; excessive urinary coproporphyrin; blood ALAD, $131 \mu \mathrm{mol} \mathrm{PBG} / \mathrm{h}$ per 1 red blood cells (at pH 6.9). In this patient endogenous zinc was assumed to be $0.131 \mathrm{mmol} / 1$ as results in this laboratory indicated that total blood zinc levels were not affected by changes in lead levels.

ALAD activity was estimated over a pH range of 6.5 to 7.5 with the addition of zinc to the assay mixture at various concentrations as in the previous experiments (Fig. 2). Over the $\mathrm{pH}$ range, ALAD was activated in proportion to the amount of zinc added. When, for example, zinc was added to the assay at $0.15 \mathrm{mmol} / \mathrm{l}$ whole blood the observed ALAD activity was 3.7 times higher at pH 6.9 than in the control without added zinc. The increased value was equivalent to an ALAD activity of 485 $\mu \mathrm{mol} \mathrm{PBG} / \mathrm{h}$ per. $1 \mathrm{RBC}$, which fell well within the range of normal values for this series.

\section{Discussion}

The recent observations relating to the antagonistic

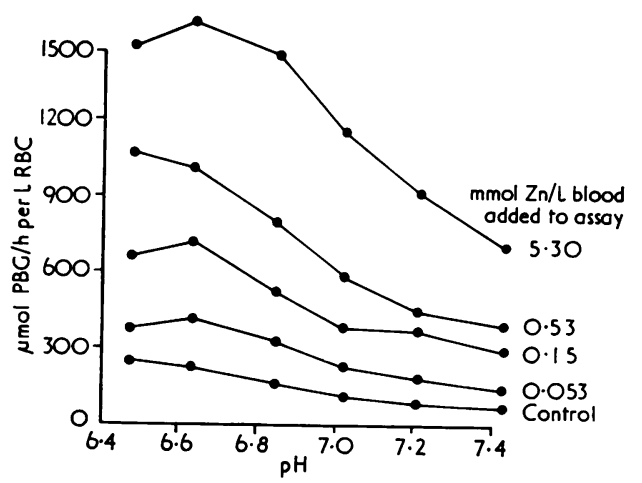

FIG. 2. The in vitro effect of exogenous zinc on the activity of ALAD in a worker with occupational lead exposure. effect of zinc on lead inhibition of ALAD make it necessary to evaluate the interrelationships in the system in so far as they affect the interpretation of ALAD assay results in a clinical laboratory.

In the present study the antagonistic effect of zinc has been shown to operate dramatically at concentrations in excess of the physiological range. However, this observation is of no clinical significance unless blood samples become contaminated with zinc during collection or before analysis.

When exogenous zinc is added at low concentrations $(0.053 \mathrm{mmol} / 1$ blood) the antagonistic effect on inhibition of ALAD by lead is minimal, but this addition is equivalent to only a $40 \%$ rise from the normal endogenous level of $0.135 \mathrm{mmol} / 1$ to a total of $0.188 \mathrm{mmol} / 1$ blood.

If, however, zinc is added to the blood in vitro at $0.15 \mathrm{mmol} / \mathrm{l}$ blood so as to bring the total zinc in the sample to double the normal endogenous level, a probable physiological situation is obtained which could be expected in vivo under conditions of industrial zinc exposure. In this case we have shown that the ALAD values are appreciably higher than those obtained without the addition of zinc. The degree of antagonism by zinc across the $\mathrm{pH}$ range studied here is such that ALAD activity falls within the normal range expected and does not indicate the excessive lead burden that the body is in fact carrying. In this regard also, the $\mathrm{pH}$ of assay is important as can be seen in Figs 1(e) and 2, where a shift of $\mathrm{pH} 0.3$ from the standard assay $\mathrm{pH}$ of 6.9 can have a marked effect on the degree of antagonism exhibited by the zinc.

The antagonistic effect of zinc on lead inhibition of ALAD activity has been confirmed at concentrations that can be related to the human physiological state. The examination of patients with concomitant lead and zinc exposure may well be complicated by the factors discussed here.

We are grateful to Miss M. Simões for skilful technical assistance.

\section{References}

Abdulla, M. and Haeger-Aronsen, B. (1971). ALAdehydratase activation by zinc. Enzyme, 12, 708-710.

- - and - (1973). Antagonistic effect of zinc in relatively high concentration on inhibition of ALA-dehydratase activity by heavy metals in vitro. International Research Communication System-General Pharmacology, (73-8) 8-14-1.

Burch, H. B. and Siegel, A. L. (1971). Improved method for measurement of delta-aminolevulinic acid dehydratase activity of human erythrocytes. Clinical Chemistry, 17, 1038-1041.

Meredith, P. A., Moore, M. R., and Goldberg, A. (1974). The effects of aluminium, lead and zinc on $\delta$-aminolaevulinic acid dehydratase. Biochemical Society Transactions, 2, 1243-1245.

Received for publication 24 September 1975 Accepted for publication 1 December 1975 